International Journal of

BioScience and Applications

\title{
Qualitative Study on Company Internal Facilitator Qualification Acquisition and Activity Experience
}

\author{
Hye-Rim Cho' ${ }^{1}$, Eun-Hee Park ${ }^{2}$, Su-Hyun Kim ${ }^{3}$, and Soon-myeong Park ${ }^{1 *}$ \\ ${ }^{1}$ Korea Expressway Corporation, Republic of Korea \\ 2 Department of Nursing, Kwangju Women's University, Republic of Korea \\ ${ }^{3}$ Department of Nursing, Nambu University, Republic of Korea
}

\begin{abstract}
${ }^{1}$
Background/Objectives: The purpose of this study is to explore the long-term meaning of facilitator qualifications and their activities within a company. For this purpose, semi-structured interviews were conducted with 13 employees of Company A who obtained advanced (master) qualifications among In-company facilitator qualifications operated by Company A. Methods/Statistical analysis: A phenomenological analysis was performed on the interview data to derive the main results. Findings: First, the motivation to participate in the in-house facilitator was that they were in charge of work, so they could be classified for the same reasons as recommendation, liking for lectures, and motivators participating. Second, the meaning of the in-house facilitator at the time of retrospective can be divided into personal, social, and occupational aspects. Third, the long-term meaning of acquiring and performing in-house facilitator qualifications is to personally find confidence in company life. However, the meaning of In-company facilitator qualification acquisition and activity experience differed according to personal inclinations or experience prior to qualification acquisition. Improvements/Applications: Based on the research results, policy implications related to the operation of the internal qualification system were suggested.
\end{abstract}

\section{Index Terms}

Company Internal Qualifications, Facilitator, Public Enterprise, Phenomenological Study

\footnotetext{
Corresponding author : Soon-myeong Park

trustpsm@gmail.com

- Manuscript received April 15, 2021.

- Revised May 14, 2021 ; Accepted June 1, 2021.

- Date of publication June 30, 2021

(C) The Academic Society of Convergence Science Inc.

2619-8363 @ 2021 IJBSA. Personal use is permitted, but republication/redistribution requires IJBSA permission.
} 


\section{INTRODUCTION}

In-company qualification system is a qualification that is operated with its own standards within an individual company, unlike national technical qualifications. There are many places where companies are using it as an effective mechanism for the development of human resources for workers [1]. In-company qualifications are especially meaningful in the public sector for fostering experts and improving the change capacity of members. In the public sector, the organizational structure is bureaucratic and compensation is centered on promotion. Many members are more interested in acquiring a higher position as a general manager than in improving their professionalism [2]. In this structure, it is difficult to be recognized as the professional competence of the members. Organizations are making efforts to compensate for excessive desire for promotion and secure expertise by preparing a system that can separately reflect professional qualifications, including internal qualifications, in personnel and compensation.

Since 2006, A public corporation has prepared and fostered Six Sigma and internal facilitator qualification systems to strengthen capacity and secure momentum for innovation in public corporations. Among them, the qualified internal facilitator acted as a kind of workshop host for the rapid discovery and progress of on-site innovation tasks, mainly at the level of assistant managers and managers. A maximum of 135 people were nurtured by opening an internal company facilitator training course. It was selected as an exemplary case of other companies and showed a lot of influence on public companies.

Facilitation, in its general sense, is an activity that facilitates and helps a team, group, or individual to effectively solve a problem at hand and achieve a goal [3]. Human resource development needs to provide a place for dynamic critical reflection that considers not only the horizontal exchange between learners and facilitators, which is a typical form of education, but also the influence of social systems and political power [4]. Facilitators contribute to organizational learning and performance creation in various fields as experts [5]. The basic qualities required of a facilitator can be broadly divided into forming a friendly relationship with customers, creating a participatory environment, stimulating group creativity, and producing effective results [6]. Not only professors, but also corporate leaders, trainers, and volunteers are playing a role as facilitators and expanding their scope [7]. In a general sense, a facilitator is a person whose role is to facilitate and help a team, group, or individual solve problems and achieve goals effectively [8-9]. In the field of human resource development, the discussion on critical human resource development is gradually increasing while criticizing the fact that traditional human resource development emphasizes learning only at the level of maintaining the status quo and accepting existing rules and assumptions [10-13].

However, according to the various contexts of internal qualifications, there is still a lack of research that in-depth reveals the meaning and changes that internal qualifications have due to their qualifications and activities. In fact, the effect of the internal qualification system within a company is not only official such as personnel and compensation, but also the recognition received informally by the organization, the sense of camaraderie and loyalty felt by the same qualifications, and the burden and self-esteem of having to show high-quality activities and performance as qualified persons. Various aspects such as development desire may appear. Since many of the internal qualifications are made to actively utilize qualified persons within the company, it is expected that this will have an impact in terms of attracting attention within the organization as the subjects of co-workers or activities often become corporate seniors and juniors. In the public sector, which is selected through large-scale recruitment and has a long tenure, it is highly likely that internal qualification activities within a company during a specific period will have an impact on the members of the organization by stigmatizing the individual for a long time.

A company's internal facilitator qualification and activities were intensively carried out by qualified persons during a specific period. It is an example that can abundantly show the influence of the activities of these internal qualified persons in the sense that the activities had an impact on individuals afterward. Therefore, in this study, through a qualitative study on the qualifications and activity experiences of 12 master facilitators who acquired the internal facilitator qualifications and performed intensively in the company A since 2006, the meaning and individual and its impact on the organization. This study will help organizations to deeply understand, carefully design and enrich the impact of internal corporate qualifications systems.

The purpose of this study was to explore the implications of acquiring internal facilitator qualifications for them and their impact on individuals and organizations through a qualitative study on the qualifications and activity experiences of internal facilitator qualifications. The specific research goals are as follows. 
First, what are the motives for acquiring qualifications and activities of internal facilitator qualifications?

Second, what is the meaning of the qualifications and experience of internal facilitator qualifications?

Third, what effect did the qualification acquisition and activity experience of internal facilitator qualifications have?

\section{MATERIALS AND METHOD}

\section{A. Study Design}

In this study, the phenomenological research method proposed by Giorgi [14] was used to explore the meaning of the experience of facilitator activities within a company. The phenomenological research method is a qualitative analysis method that examines people's perceptions and experiences of a specific phenomenon in depth. It has been suggested in various ways by several researchers such as Colaizzi [15], Giorgi [14], and van Manen [16]. Focusing on the experiences of the research subjects, the focus is on understanding and describing the essence of the research subject through reflection rather than generalization. Compared with other analysis methods, Giorgi's analysis method [14] explains in detail the uniqueness of each research participant in situational and structural statements, and has the characteristic of integrating the experiences of all research participants in general and structural statements [17]. Giorgi [14] called this method 'empirical phenomenological analysis'. Above all, empirical or objective data were collected in the form of a description or interview on a topic that is a phenomenon that pursues the essential structure of the research object. Through in-depth research on the technology of these research subjects, the focus is on revealing the meaning of living experience in more detail.

Giorgi [14] suggested four specific steps as a phenomenological research method: overall recognition, semantic unit classification, transformation into academic terms, and integration of the transformed semantic unit into a structure. These procedures allow for meaningful and appropriate delivery to the reader through academic significance and structural integration while researching on the basis of concrete statements from the participants' vivid experiences.

\section{B. Research Process}

1) Research subjects and data collection

This study was conducted with those who experienced internal facilitator activities in A public company. Ten people were selected by the following procedure. In this study, 36 master-level facilitators who were most active at the time were selected to secure subjects who could provide the most appropriate information on the research topic. They had at least 30 hours of workshop progress. Among them, the contents and purpose of the study were explained in turn from among the employees with the highest mileage, excluding those who were leaving the company or taking a leave of absence, and then whether or not they were interviewed was checked. As a result, 12 people were interviewed.

Before the study, the purpose, characteristics and significance of the study were informed to the participants in advance, confidentiality and anonymity were explained, and then a semistructured interview was conducted. One of the researchers worked as an internal facilitator with them 12 years ago and is currently in charge of HRD work, so it was possible to form a rapport with the participants and understand the context. However, such an environment may act as a prejudice for researchers, and there is a risk that it will be difficult for research participants to give honest answers as colleagues who can be seen in company life in the future. The researcher asked the study participants for an honest response, recalling the meaning of the event 15 years ago and the response to the subsequent impacts, recalling that they now have their own place in the company. Efforts were made to maintain a professional distance while interacting with the participants. At the end of the interview, a gift was provided to the study participants to encourage voluntary and sincere participation.

Interviews were conducted from February to March 2020 as a whole, and one or two interviews were held per person. On average, each interview took about 60 minutes. At the time of the subjects' activities, their positions were at the assistant manager level, and now they were at the manager level and deputy manager level. There were 5 males and 7 females. The present age ranged from 24-29 years old.

\section{2) Data analysis}

The study participants performed data analysis according to the method of Giorgi (1997). First, in the stage of recognizing the whole, the researchers transcribed the entire recorded description and read it freely and repeatedly in order to derive a general perception from the participants' statements about their experiences. In order to preserve the content and atmosphere when writing the manuscript, it was done immediately after the interview. Second, it was classified into natural meaning units suitable for the research topic among the entire texts. This is because the purpose of the study can be achieved only when 
the text is decomposed into processable units. At this stage, comparison was made with the researcher's experience or literature knowledge, and care was taken not to criticize or skeptical. Third, after combining the divided semantic units and subjecting them to themes, the researcher transformed the focal meaning into an appropriate academic term through the process of reflection. Fourth, the derived central meaning was structurally integrated and expressed as a coherent description. In this process, we tried to create a more valid structure by reflecting the opinions of researchers with rich experience in qualitative research. This integration process can reveal the essence of the phenomenon or the essential theme of all transformations by identifying common features that appear throughout specific cases [18]. While adhering to this method of Giorgi (1997), researchers tried to maintain a scientific attitude through description and analysis focusing on the linguistic texts of subjects.

In order to secure objectivity while deriving the central meaning and structure of the data, the research process and results were evaluated and adjusted by other researchers, such as professors and doctoral professors in vocational education and human resource development. Through iterative and cyclical consensus among the researchers, the validity of the tentatively derived structure and the original data was compared and checked, the names of each component were revised, and the data were rearranged.

\section{RESULT AND DISCUSSION}

In-depth interview data of 10 research participants selected to explore the meaning of company A's internal facilitator activities were analyzed. The individual experiences of the study participants were derived as three sub-factors in the area of motivation for participation, the meaning at the time of the activity as three sub-elements, and the influence at the company after the activity as two sub-elements.

\section{A. Motives for participation and qualification of in-house facilitators}

The motivation for participating as an internal facilitator of company $\mathrm{A}$ and the motivation for acquiring a qualification could be divided into several categories as follows. First, in the early stages of the introduction of the internal facilitator system, the company recruited participants through an official letter. At this time, 12 people participated for the first time, and most of the participants were people who worked as CS instructors inside the company. Among them, 6 of them obtained the master's qualification and continued to participate as facilitators. After that, as the company boomed, there were people who were interested.

After that, I participated for various reasons, but after February 2007, the contents of nurturing and educating internal project facilitators for each institution were included in the institutional evaluation for a boom in innovative activities. At the same time, the institution encouraged participants to participate in "those who could do it," that is, unmarried positions within three years of joining the company (there were many advantages, such as freedom from business trips). In order to receive excellent evaluation, the person in charge of the relevant indicator has in some cases acted as a facilitator. However, those who did not fit into the facilitator activities were forced to participate, and even if they did, they did not attend often.

Some expressed that they liked being a facilitator. Among the various aspects of facilitator activities, the preferred aspect varied in nature. For example, they expressed that they liked to meet and talk with new people, or because they liked to do new things outside of the existing work environment.

The motives for participating as an in-house facilitator could be classified for the same reasons as duty, good activities, people, and similar experiences.

\section{1) Compulsory to participate}

In the case of compulsory participation, there are cases in which participation is first requested or directed by a supervisor. Supervisors encouraged participation in the facilitator activity in the expectation that participation in the facilitator activity would have a positive effect on the study participants. In addition, in some cases, participation was made due to an internal policy promoted to revitalize the facilitator system. Each institution had a policy to select a certain number of people as facilitators, but in some cases, they were designated as facilitators. On the other hand, in some cases, participation was made because the performance of facilitator activities was included in the evaluation of the institution.

Suddenly, the branch manager said, 'You go here,' so I went without knowing what it was." The Innomeeting(innovation+meeting) was held at the recommendation of Deputy Manager Shin. At that time, training for new employees was something like this... During the discussion process, I did things like secretary and secretary, but I think they saw it there and told me to do it."

"At the time, most of the young female employees 
were the focus of the Innomeeting(innovation+meeting) at the head office, but at the head office, the person to do it was just me, naturally." "If the head office asks for it, it evaluates it and connects them together... (skip the middle) So, I just sent myself, the master Innocody (innovation + cody)."

\section{2) Participated in facilitator activities because I} liked it

The main reason that the study participants were interested in facilitator activities was that they were able to come into contact with new jobs, places, and people. Many study participants expressed that the process of learning new things they did not know was fun. There were also responses that it was good to be able to get away from the existing work environment for a while. The study participants said that they enjoyed helping the subjects participating in the workshop through facilitator activities, and some expressed in detail that it was good to be paid for the activity.

"It was a different job from what I was doing at the company, so I was able to get into a new field of work and meet different people. It gave me something new."

"Actually, I was frustrated with the company. While the company wasn't having any fun, I think the Innocody(innovation + cody) activity suited my needs. It felt like I was getting away from work for a while. It felt like an affair."

"I think the feeling of helping (workshop participants) to come up with a lot of ideas, allowing ideas to come out, and making it possible to put them into practice was really good."

"It was fun. give me money there I think it was paid in cash back then."

\section{B. Acquisition of in-house facilitator qualifications and the meaning of activities}

The meaning of internal facilitator activities in the company retrospected at the present time can be divided into personal, social, and occupational. First, it was stated that although facilitator activities were a burden in common from the personal aspect, they were motivated for self-development such as learning or acquiring professionalism. The internal facilitation activity within the company is still new within the existing organization, and those who were performing auxiliary tasks under the team leader and part leader suddenly take charge of topic discussions for several hours or two to three days with 20 to 40 people. At this time, the overall decision-making process, such as the workshop process method, textbook preparation, and role sharing, was made independently by Innocody(innovation+cody) without going through the approval line. For example, the master Innocody(innovation+cody) becomes the pm of the workshop project and collaborates with the senior and junior Innocody(innovation+cody) to produce the best results. In other words, there was novelty because broad decision-making authority, which is difficult to make in the field of work, was given to lower-level personnel in the name of experts and qualified persons.

In addition, the results of internal facilitation activities within the company were immediately fed back and could be fed back repeatedly. In other words, it was possible to know whether the workshop results were good or bad, and whether the participants' responses were positive or negative, and such reflections were made through the facilitators through post-workshop meetings. Facilitators strive to create more meaningful results in their organizations.

Another was that there was a negative view of facilitation activities, so facilitators had to be 'separated people'. In other words, during the workshop, 'what do you do by doing this? Would it make a difference to the company by doing this?' Most of these participants were in rank and older than the facilitator. In order to perform this role, it is necessary to have enough knowledge and skills on how to conduct a workshop, but there was a burden in this regard.

Nevertheless, there was an opinion that the workshop was able to proceed better than expected, and it was that the facilitators had a greater advantage than the attendees on how to proceed with the Innomeeting(innovation+meeting), so trust was gained. In other words, even if the total amount of experience within the company and the awareness of the subject matter, even if there are more workshop participants, the workshop progressing process and skills are more for facilitators although the years are small, and the overall power is given to the facilitators. There was also an advantage. In other words, even if the participant was in a higher rank than himself (team leader, branch manager, or even a manager), the assistant-level facilitator instructs the process or answers questions. The workshop started with decision makers within the institution, and they were also empowered by their participation back and forth.

This situation was both a pride and a burden for the facilitators, and when the workshop was 
successfully completed after overcoming various preparation processes and difficulties, the facilitators felt rewarded and felt a sense of camaraderie in the process. Also, the facilitators felt that these activities were 'not our company'. First, there was no way to freely express opinions beyond ranks and decide by voting (NGT method). In the process, only the right to vote could be exercised even if the position was high. At Innomeeting(innovation+meeting), Innocody(innovation+cody) was able to act as an expert.

"He also said that the facilitators themselves were 'people you don't normally see in our company'. "Public enterprise workers generally fulfill the responsibilities assigned to them by the division of work and may be inclined to avoid additional work. There is no need to go out and work overtime or go on a long business trip. However, the fellow facilitators I saw at that time had a passion for participating in business trips after finishing their work overtime."

\section{Conclusion}

The purpose of this study was to explore the meaning of acquiring internal facilitator qualifications to them through a qualitative study on the qualifications and activity experiences of internal facilitator qualifications. To this end, an in-depth interview was conducted focusing on the motives of qualification acquisition and activity, the meaning and impact of qualification acquisition and activity experience, and the main results and suggestions are as follows.

Responsibilities and authority are stipulated for each job and position in the organization, and in general, the higher the position, the greater the responsibility. However, the qualification system grants the authority to work beyond the role of the position within the system in which the qualification operates. For example, in a workshop in which the team leader level or higher participates, a qualified facilitator with a lower rank is given the authority to conduct the entire workshop and can manage work or time management for each process. These activities can be a burden to the in-house facilitator, but they can also be an opportunity for motivation or growth. In other words, it can be a challenge while performing a larger role beyond the roles limited to the existing duties and ranks. The strict scope of responsibility of the existing bureaucratic organization can hinder the full expression of individual capabilities, which means that new responsibilities through the qualification system can infuse flexibility and vitality to the organization.
Because the facilitator's reflection affects the whole process of facilitation, it also affects the learner's reflection and learning outcomes [18-21].

First, in terms of motivation, facilitator activities were good, so there were quite a few people who participated voluntarily. They were able to participate in extracurricular activities because they could feel a sense of satisfaction and vitality that they could not feel in their previous job while working as a facilitator. In an organization, an individual works like a checkerboard. In the process, individual interests and abilities are sometimes reflected, but in many cases the given role is mechanically performed.

Second, it was an opportunity to identify competent individuals from the organizational point of view. In fact, there were cases where the company moved to related jobs (headquarters planning team, headquarters strategy department) after the company's internal facilitator activity. Basically, problem-solving skills, planning skills, and presentation skills are all necessary for facilitator activities.

\section{REFERENCES}

[1] Lee, D. I. \& Kim D. G. (2003). A Scheme to Improve In-Firm Qualification Systems Enhancing HRD in Firm, The Journal of Vocational Education Research, 22(2), 147-163.

[2] Park, S. M. \& Na, S. I. (2017). Career Paths, Characteristics, and Related Variables of Office Workers in Public Corporations, Korean Public Personnel Administration Review, 16(1), 177-208.

[3] Schwarz, R. M. (2002). The skilled facilitator: A comprehensive resource forconsultants, facilitators, managers, trainers, and coaches (2nd ed.). San Francisco, CA: Jossey-Bass.

[4] Trehan, K. (2004). Who is not sleeping with whom?: What's not being talked about in HRD? Journal of European Industrial Training, 28(1), 23-38.

[5] Hogan, C. (2002). Understanding facilitation: Theory \& principles. London, UK: Kogan Page.

[6] Wardale, D. (2008). A proposed model for effective facilitation. Group Facilitation: A Research \& Applications Journal, 9, 49-58.

[7] Lee, J., \& Kolb, A. (2013). Facilitation skills in management education Group techniques to guide management situations. Andragogy Today: International Journal of Adult \& Continuing Education, 16(2), 175-198.

[8] Bens, I. (2008). Facilitation at a glance!: A pocket guide of tools and techniques for effective meeting facilitation. D. Picard (2nd ed.). Joint publication of GOAL/QPC, AQP.

[9] Weaver, R. G., \& Farrell, J. D. (1997). Managers as facilitators: A practical guide to getting work done in a changing workplace. San Francisco, CA: BerrettKoehler Publishers.

[10] Elliott, C., \& Turnbull, S. (Eds.). (2004). Critical thinking in human resource development. Critical 
[11] Thinking in Human Resource Development. pp.1-7. New York, NY: Routledge.

[12] Rigg, C., Stewart, J., \& Trehan, K. (Eds.). (2007). A critical take on a critical turn in HRD. Critical human resource development: Beyond orthodoxy. pp. 1-16. Upper Saddle River, NJ: Prentice Hall.

[13] Trehan, K., \& Rigg, C. (2005). Beware of the unbottled genie: Unspoken aspects of critical selfreflection. In Elliott, C., \& Turnbull, S. (Eds.). Critical thinking in human resource development. pp. 11-25. New York, NY: Routledge.

[14] Vince, R. (2004). Ideas for critical practitioners. In Elliott, C., \& Turnbull, S.(Eds.). Critical thinking in human resource development. pp. 26-36. London: Routledge.

[15] Giogia, A. (1997). The theory, practice, and evaluation of the phenomenological method as a qualitative research procedure. Journal of Phenomenological Psychology, 28(2), 235-260

[16] Colaizzi, P.F. (1978). Psychological research as a phenomenologist views it. In: Valle, R.S. and King, M., Eds., Existential-Phenomenological Alternatives for Psychology, Oxford University Press, New York, 48-71.

[17] Van Manen, M. (1990). Researching lived experience: Human science for an action sensitive pedagogy. Albany: State University of New York Press.

[18] Im, M. Y. \& Kim, Y. J.(2010). A Phenomenological Study Experience of Suicide Attempt in Old Age, Journal of Family Relations, 15(3), 175-196.

[19] Brockbank, A., \& McGill, I. (2007). Facilitating reflective learning in higher education (2nd ed.). New York, NY: McGraw-Hill International.

[20] Thomas, G. (2004). A typology of approaches to facilitator education. Journal of Experiential Education, 27(2), 123-140.

[21] Kember, D., Leung, D. Y., Jones, A., Loke, A. Y., McKay, J., Sinclair, K.,Tse, H., Webb, C., Wong, F., Wong, M., \& Yeung, E. (2000). Development of a questionnaire to measure the level of reflective thinking. Assessment \& Evaluation in Higher Education, 25(4), 381-395.

[22] Peltier, J. W., Hay, A., \& Drago, W. (2005). The reflective learning continuum: Reflecting on reflection. Journal of Marketing Education, 27(3), 250-263. 